http://jmscr.igmpublication.org/home/

ISSN (e)-2347-176x ISSN (p) 2455-0450

crossref DOI: https://dx.doi.org/10.18535/jmscr/v9i11.05

Journal Of Medical Science And Clinical Research

IGM Publication

An Official Publication of IGM Publication

\title{
Anaesthetic Management of a Large Degenerative Leio Myoma Mimicking as an Ovarian Tumour: A Case Report
}

\author{
Authors \\ Dr Chethana.CH*, Dr Arun Kumar \\ *Corresponding Author \\ Dr Chethana.C \\ III Year Postgraduate, Department of Anaesthesiology, Chettinad Hospital and Research Institute, \\ Kelambakkam
}

\begin{abstract}
Giant tumors /huge mass are rarely seen with the advanced medical sciences and modern technology. These are mainly characterised by its huge size causing pressure symptoms apart from basic pathology. leiyomyosarcoma is an aggressive soft tissue sarcoma a reltively long surgery with major blood loss made this procedure challenging for the anaesthesiologist in maintaining euvolemia and hemodynamic stability without causing acidosis, organ damage, coagulopathy and acute kidney injury.

Here we are reporting a case of 41 year old pre menopausal nulliparous woman with huge degenerative leio myoma of $20 \mathrm{~kg}$ mimicking as a n ovarian tumour successfully removed and managed by meticulous peri-operative management.

Keywords: Leiyomyoma, Large mass, Anaesthetic management.
\end{abstract}

\section{Introduction}

Leiomyoma of the uterus is the most common tumor of the female pelvis, arising from the uterine smooth muscle. ${ }^{1}$ Large myomas with degenerations located towards the adnexa may mimic an ovarian neoplasm and can impose a challenge in its diagnosis. Radiological modalities like ultrasonography and MRI may aid in differentiating the two. We report an unusual case of a large, cystic, pedunculated uterine leiomyoma mimicking an ovarian tumor which missed the radiologist and the surgeon pre-operatively.

\section{Case Report}

A 41 year old premenopausal nulliparous woman presented with huge abdominal swelling. the swelling has increased gradually over past 3 years to attain the present size. Weight of the patient was $95 \mathrm{~kg}$. Patient is a known hypertensive and on tab. amlong 5mg BD and Tab.Telma40mg OD for 2 years and hypothyroid and is on Tab.

Thyronorm 12.5 micgm OD. She is a newly diagnosed diabetic and on meal plan. History of diagnostic laproscopic surgery for primary infertility under General Anaesthesia and was uneventful. Shw was scheduled for staging laprotomy. CT showed well defined solid cystic lesion of size $24.5 \mathrm{~cm} \times 33.8 \mathrm{~cm} \times 24.3 \mathrm{~cm}$

Her pre-anaesthetic evaluation did not reveal any abnormalities except for TSH-6.28. Her Preoperative vitals were Heart rate-78 per minute, blood pressure-140/90mmHG and oxygen 
saturation (SPO2) of $99 \%$ at room air.on anticipation of prolonged surgery and major blood loss, adequate blood products reserved.

On arrival to operating room, she was started on large bore IV cannula (16G) on the left hand and ASA monitors like Electroencephalogram (ECG), Non-invasive blood pressure monitoring (NIBP), pulse oximetry were attached. Epidural catheter was secured in T11-T12 interspace and right radial artery was cannulated using 20G cannula for monitoring of blood pressure. Anaesthesia was then induced with inj. Propofol/inj. Fentanyl and paralysed with Inj. Atracurium. Maintained with oxygen/air/isoflurane. Airway secured with size 7.5 ETT, and fixed at $20 \mathrm{~cm}-\mathrm{BAE}+$.temperature monitoring done through nasopharyngeal probe. intra operative analgesia was provided by inj. Morphine/inj. Fentanyl IV. Warm fluids for volume resuscitation and surface warmers were used to prevent hypothermia. the total surgical time lasted for 510minutes and the blood loss was calculated to be approximately $2000 \mathrm{ml}$. intra operatively 4 units of prbc were transfused along with $4500 \mathrm{ml}$ of crystalloids and $1000 \mathrm{ml}$ of colloids. epidural infusion started with inj. $0.125 \%$ Bupivacaine with $2 \mathrm{mcg} / \mathrm{ml}$ inj. Fentanyl at $6 \mathrm{ml} / \mathrm{hr}$. After completion of surgery she was shifted to ICU for monitoring and epidural infusion continued.

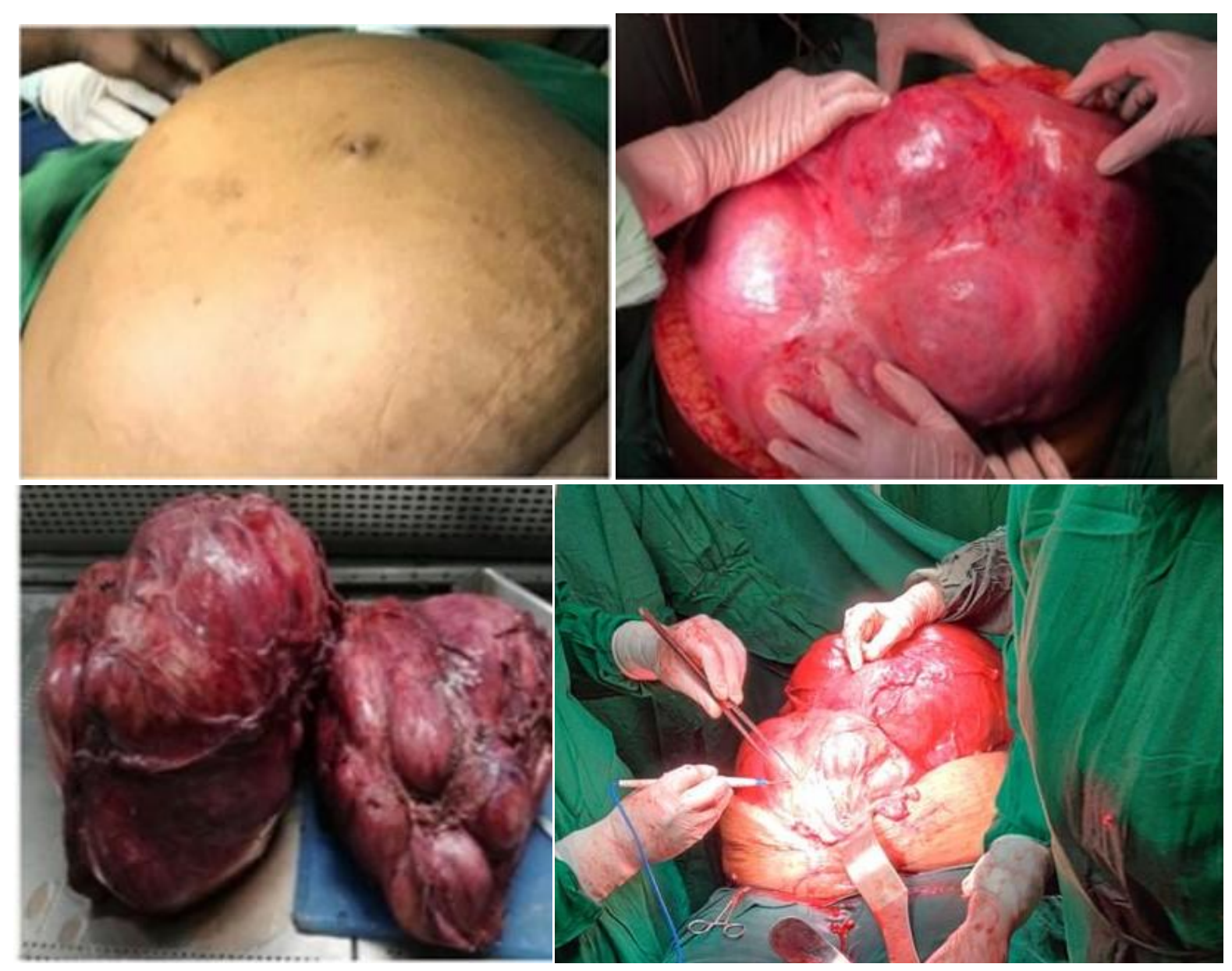

\section{Discussion}

The main anaesthetic concerns of our patient:

1. The giant mass may compress the major vessels causing hemodynamic instability.

2. Bleeding Diathesis
3. Mass affect decreasing the lung compliance

The main concern in our case was the haemorrhagic shock caused by major blood lossit's a life threatening condition causing hemodynamic instability with decreased tissue 
perfusion and hypoxia causing organ damage. adequate blood products were reserved and it was ensured. To meet the anticipated major blood loss, two large bore wide cannulas were secured. Warm fluid was made available for large volume resuscitation to prevent hypothermia.

Complications of massive transfusion are acidosis, hypothermia, coagulopathy, hypocalcemia and TRALI (transfusion related acute lung injury) . No such complications were seen in our patient. $10 \mathrm{ml}$ of $10 \%$ calium gluconate IV given intraoperatively. Core temperature was monitored and maintained at 35 to $36 \mathrm{deg}$ celcius. Urine output was maintained at $1 \mathrm{ml} / \mathrm{kg} / \mathrm{hr}$.

\section{Conclusions}

Surgical bleeding is an emergency with high mortality and it leads to hypovolemic shock-hence requires effective anticipation and treatment.

It may also lead to coagulopathy, due to consumption and dilution of clotting factors. hence bleeding control, adequate tissue perfusion, oxygenation, maintaining normothermia, correction of anaemia, acidoses, electrolyte abnormalities, use of appropriate blood products are the key points in successful management.

\section{Reference}

1. Khanuja E, Tyagi M, Gupta S, et al. Leiomyoma with degeneration mimicking an ovarian neoplasm. Int J Pregn \& Chi Birth. 2017;2(3):64-65.

DOI: 10.15406/ipcb.2017.02.00020

2. Aydin $\mathrm{C}$, Eriş $\mathrm{S}$, Yalçin $\mathrm{Y}$, et al. A giant cystic leiomyoma mimicking an ovarian malignancy. Int $J$ surg case rep. 2013;4(11):1010-1012.

3. Monappa Geeth. Leiomyomas Masquerading As Ovarian

Neoplasms. IOSR Journal of Dental and Medical Sciences. 2015;14(7):5-9. 